\title{
Pemberdayaan Masyarakat Desa Cileuksa Dalam Meningkatkan Perekonomian Masyarakat Melalui UMKM
}

\author{
Ari Soeti Yani ${ }^{a, 1, *}$, Fauziah ${ }^{b, 2}$, Rio Johan Putra ${ }^{b, 3}$, Mila ${ }^{\text {b,4 }}$ \\ ${ }^{a, b}$ Fakultas Ekonomi dan Bisnis Universitas 17 Agustus 1945 Jakarta \\ 1 arisoetiyani@gmail.com* \\ * corresponding author
}

ARTICLE INFO

Keywords

How To Get Capital; Manage MSME Capital; Taxation

\begin{abstract}
This Community Service Program aims to empower the people of Cileuksa Village to improve the community's economy through MSMEs. Cileuksa Village is one of the villages in Sukajaya District, Bogor Regency, West Java Province. In the village of Cileuksa there is also a lack of awareness in managerial business management and tax aspects of MSMEs. Success in managing a business is largely determined by the expertise of business actors in obtaining sources of capital and procedures for managing finances, plus knowledge in terms of regulations such as taxation and related rules in the MSME business sector, such as MSME taxes and regulations regarding goods for consumption must be fulfilled and implemented. Limited knowledge is one of the challenges that must be faced by rural communities in managing their business, so that village MSME businesses can run, it is necessary to have socialization on how to obtain and manage MSME capital and know taxation.
\end{abstract}

\section{PENDAHULUAN}

Desa Cileuksa merupakan salah satu desa di Kecamatan Sukajaya Kabupaten Bogor Jawa Barat. Desa tersebut berada di Kawasan Taman Nasional Gunung Halimun - Salak. Desa tersebut merupakan destinasi wisata dan yang termasuk perbatasan dengan Provinsi Banten. Desa Cileuksa termasuk Desa yang cepat berkembang dan sangat maju, hal ini terbukti dengan adanya usaha IbuIbu PKK yang sebagai pendorong sekaligus yang mendirikan UMKM kripik pisang. UMKM kripik pisang selain dipasarkan di Jabodetabek juga sudah memasuki diluar Provinsi Jawa Barat tepatnya di Provinsi Lampung.

Desa Cileuksa banyak dikunjungi pengunjung karena tempatnya memiliki pesona alam yang sangat indah. Masyarakat desa Cileuksa sangat terbuka dan bergotong royong dalam menjalankan semua kegiatan, contohnya Desa tersebut mempunyai unggulan produk UMKM yaitu kripik pisang yang diolah bersama-sama Ibu-Ibu PKK.

Keterbatasan pengetahuan menjadi salah satu tantangan yang harus dihadapi oleh masyarakat dalam mengelola bisnis UMKM tersebut, agar bisnis ini dapat berjalan lancer perlu adanya sosialisasi yaitu tentang bagaimana cara mendapatkan modal dan mengelola modal UMKM serta memberikan pengetahuan dalam hal regulasi seperti perpajakan dan aturan yang terkait dalam sektor bisnis UMKM tersebut sehingga masyarakat memiliki kesadaran untuk membayar pajak.

Tujuan yang diharapkan dengan adanya kegiatan ini khususnya masyarakat desa Cileuksa yaitu dapat meningkatkan perekonomian masyarakat setempat.

Adapun kegunaan kegiatan ini khususnya masyarakat Desa Cileuksa lebih memahami dalam mengelola bisnis UMKM tersebut sehingga perekonomian masyarakat berkembang dengan cepat dan dapat meningkatkan kelangsungan hidup UMKM di masa yang akan datang, dan menambah pendapatan keluarga. 


\section{PERMASALAHAN}

Masyarakat Desa Cileuksa pada umunya mempunyai mata pencaharian yaitu petani. Para petani Desa Cileuksa mendapatkan lahan pertanian secara turun-temurun. Menurut masyarakat Desa Cileuksa lahan yang ditinggalkan oleh leluhur mereka harus dijaga dan dilestarikan. Desa Cileuksa memiliki lahan yang sangat subur, setiap seminggu sekali masyarakat menikmati hasil panennya baik itu sayur-mayur, buah-buahan, maupun usaha UMKM kripik pisang yang sebagai tambahan penghasilan.

Masyarakat Desa Cileuksa juga masih minim pengetahuan dalam pengelolaan keuangan bisnis mereka serta masalah perpajakan.

Permasalahan dalam aspek teknis operasional pengelolaan keuangan UMKM di Desa Cileuksa Kecamatan Sukajaya Kabupaten Bogor adalah sebagai berikut:

1. Pengetahuan yang minim mengenai cara mendapatkan modal UMKM

2. Pengetahuan yang minim cara mengelola modal UMKM

3. Pengetahuan yang minim mengenai aspek pajak usaha UMKM

4. Pengetahuan yang minim mengenai aspek regulasi yang harus dipenuhi dalam menjalankanbisnis UMKM

5. Kebutuhan mengenai pengetahuan manajemen keuangan dan operasional dalam meningkatkan bisnis UMKM desaCileuksa

6. Belum adanya koperasi yang menangani usaha UMKM di Desa Cileuksa

\section{METODE PELAKSANAAN}

Pelaksanaan program pengabdian kepada masyarakat ini yaitu penyuluhan dan pelatihan. Adapun uraian kegiatan tersebut sebagai berikut:

a. Program penyuluhan/sosialisasi tentang:

- Cara mendapatkan modal UMKM

- Cara mengelola modal UMKM

- Aspek pajak usaha dan aspek regulasi seperti perpajakan dan aturan yang terkait dalam sector bisnis UMKM

b. Program pelatihan

- Bagaimana cara mengembangkan/inovasi produk, seperti mengelola pisang selain menjadi kripik pisang. Juga bolu pisang, dan lain-lain.

- Bagaimana cara memasarkan melalui online

- Bagaimana cara membentuk koperasi

Partisipasi mitra didalam kegiatan penyuluhan dan pelatihan yaitu dengan menyediakan fasilitas-fasilitas tempat untuk pelaksanaan kegiatan tersebut yaitu di Balai Desa Cileuksa sebagai tempat pertemuan. Instrumen yang digunakan pada program pengabdian kepada masyarakat ini meliputi: (1). Sound System, (2). Kursi, (3). Proyektor, (4). Kamera, dan lain-lain.

Lokasi kegiatan adalah di Desa Cileuksa Kecamatan Sukajaya Kabupaten Bogor, Jawa Barat. Waktu pelaksanaan sejak mulai persiapan dari bulan Mei sampai dengan pelaksanaan mulai tanggal 20-21 Agustus 2018.

\section{HASIL DAN PEMBAHASAN}

Pengabdian masyarakat di laksanakan sesuai jadwal yang dibuat sebelumnya. Peserta yang hadir telah menempati ruangan Balai Desa Cileuksa. Pelaksanaan penyuluhan dan pelatihan berjalan lancer sesuai yang diharapkan.

Peserta sangat bersemangat mengikuti jalannya penyuluhan dan pelatihan yang diberikan. Materi yang disiapkan di desain sedemikian rupa agar dapat mudah dipahami oleh warga yang hadir.

Materi juga disampaikan dengan Bahasa yang sangat sederhana agar lebih dapat dipahami dan dimengerti untuk dilaksanakan.

Pelaksanaan dilaksanakan dalam semester ganjil tahun ajaran 2018/2019 pada hari Senin dan Selasa tepatnya tanggal 20-21 Agustus 2018.

Adapun materi yang disampaikan yaitu tentang: 
1. Modal

- Modal adalah sesuatu yang diperlukan untuk membiayai operasi perusahaan mulai dari berdiri sampai berperan. Modal dalam bentuk yang diperlukan untuk membiayai segala keperluan usaha. Modal keahlian dan kemampuan seseorang untuk mengelola atau mengeluarkan modal (Fahmi, 2012)

- Kapan modal usaha dibutuhkan yaitu dari awal memulai usaha, pengembangan usaha sampai ketika ada kesulitan keuangan

- Kegunaan modal usaha yaitu untuk: (Fahmi, 2012)

a. Modal Kerja; biaya bahan baku, biaya tenaga kerja, biaya pemasaran dan lain-lain

b. Investasi; alat produksi, peralatan, tempat usaha dan lain-lain

- Syarat untuk memperoleh kredit, yaitu: (Riyanto, 2001)

a. Kesesuaian permohonan kredit dengan pasar sasaran bank dan jika tidak sesuai dengan pasar sasaran modal permohonan akan ditolak

b. Analisa Kredit; indentitas pemohon, tujuan permohonan kredit, riwayat hubungan bisnis dengan bank

c. Analisis 5C kredit (Character, Capacity, Capital, Condition dan Collateral)

- Sumber PemohonAlternattif
a. Pegadaian
b. Koperasi
c. Permodalan dari Iklan
d. Relasi bisnis, seperti supplier atau distributor
e. Pinjaman dari kantor atau teman

2. UMKM

- Kebijakan pemerintah dalam UMKM meliputi : ( Munawir, 2010 )

- Pembangunan UMKM

- Tantangan dalam membangun UMKM

- Arah strategi, kebijakan dan program pembangunan UMKM

- Pembangunan UMKM

Pembangunan koperasi sebagai wadah kegiatan ekonomi UMKM harus menjadi badan usaha, usaha efisien, Gerakan ekonomi rakyat yang tangguh dan berakar dalam masyarakat

3. Kemampuan kreatif dan inovatif yang dijadikan dasar, kiat dan sumber daya untuk mencari peluang menuju sukses. Kata Kunci kewirausahaan adalah kreatif dan inovatif. ( Alma,2009). Kreatifitas : kemamapuan mengembangkan ide dan cara-cara baru dalam memecahkan masalah dan menemukan peluang.Inovasi : kemampuan menerapkan dalam rangka memecahkan masalah dan menemukan peluang.

4. Fungsi dan Peran Wirausaha : ( Alma, 2009 ) Mikro yaitu memiliki peran sebagai penemu ( menciptakan sesuatu yang baru), yang kedua sebagai perencana yaitu merencanakan strategi usaha baru, ide-ide baru dan peluang sukses. Sedang Makro yaitu memiliki peran menciptakan kemakmuran, pemerataan kekayaan dan kesempatan kerja.

5. Menurut Harisno dan Tri Pujadi, e-commerceatau online merupakan satu set dinamis teknologi, aplikasi dan proses bisnis yang menghubungkan perusahaan, konsumen dan komunitas tertentu melalui transaksi elektronik dan perdagangan barang, pelayanan dan informasi secara elektronik (Puji, 2009: 67)

Dengan adanya penyuluhan dan pelatihan diharapkan kedepannya adanya program berkelanjutan. Hal ini dapat dilihat adanya produk unggulan UMKM Desa Cileuksa yaitu olahan pisang baru berupa kripik pisang dan stik pisang saja.

Jadi perlu adanya inovasi produk seperti bolu pisang, cake pisang dan lain-lain. Serta perlu adanya suntikan dana baik dari pemerintah maupun BUMN. Untuk itu pemerintah setempat saat ini sedang mempersiapkan BUMDES, baik gedungnya maupun ijin operasinya.

Peserta penyuluhan dan pelatihan sudah memahami perlunya bagaimana cara mendapatkan dan mengelola modal UMKM serta pengetahuan tentang perpajakan. Saat diadakan penyuluhan langsung dengan contoh-contoh yang disesuaikan dengan kondisi yang dialami oleh peserta, mereka dapat memahami dan mempraktekannya dalam simulasi. 
Perlu adanya program penyuluhan yang berkelanjutan dan berkesinambungan, guna memastikan bahwa masyarakat Desa Cileuksa dapat memanfaatkan kemampuan yang dimiliki dan pengolahan kekayaan alam untuk peningkatan kesejahteraan masyarakat sesuai dengan materi penyuluhan yang telah diberikan.

\section{SIMPULAN}

1. Masyarakat Desa Cileuksa ingin adanya program penyuluhan secara berkelanjutan seperti bagaimana memasarkan produk unggulan olahan pisang serta bagaimana cara pengemasan yang menarik konsumen/pembeli, sehingga dapat bersaing dalam dunia bisnis

2. Perlu adanya pendampingan dalam bentuk koperasi, karena dengan adanya koperasi dapat meningkatkan perkembangan perekonomian masyarakat Desa Cileuksa, khususnya bisnis UMKM

3. Program penyuluhan dan pelatihan membawa dampak yang positif dan meningkatkan kesejahteraan masyarakat Desa Cileuksa

\section{REKOMENDASI}

1. Kepala Desa Cileuksa Kecamatan Sukajaya Kabupaten Bogor Jawa Barat yang telah member waktu dan tempat kepada kami untukmelaksanakan penyuluhan di Desa Cileusa

2. Para mahasiswa yang sudah mengundang kami sebagai pembicara dalam penyuluhan tentang pemberdayaan Masyarakat Desa Cileuksa dalam Meningkatkan Perekonomian Masyarakat Melalui UMKM

\section{UCAPAN TERIMA KASIH}

UcapanTerimakasih ditujukan kepada Universitas 17 Agustus 1945 Jakarta khususnya Lembaga Pengabdian Kepada Masyarakat yang telah mendanai kegiatan penyuluhan ini di Desa Cileuksa, selain itu teman-temanDosen FEB Universitas 17 Agustus 1945 Jakarta yang telah berpartisipasi dalam penyelanggaraan acara ini

\section{Foto-foto KegiatanAbdimas}
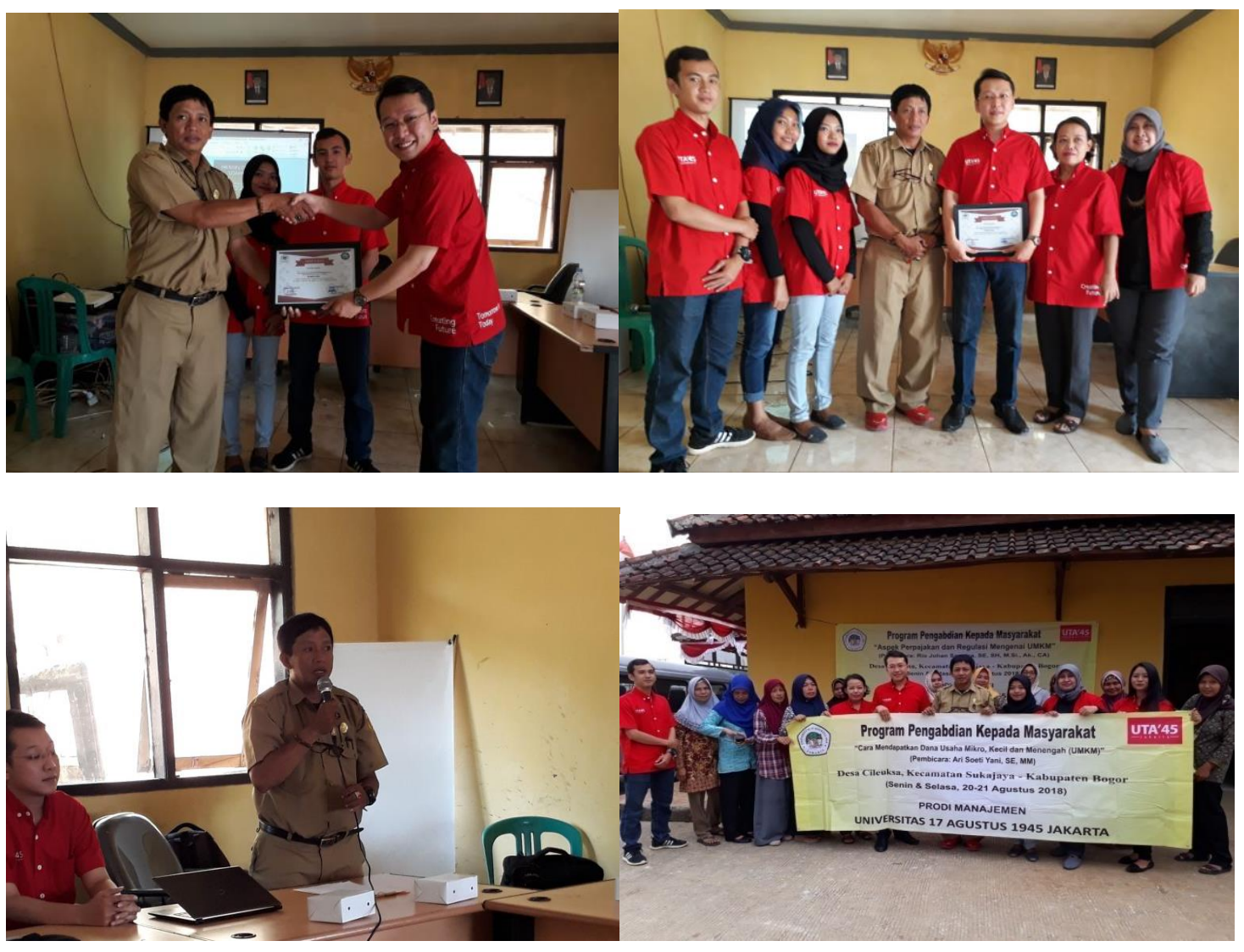


\section{DAFTAR PUSTAKA}

Alma, Buchari, 2009, Kewirausahaan, Alfabeta, Bandung.

Fahmi, Irham, 2012, “Pengantar Manajemen Keuangan”, Penerbiat ALFABETA, Bandung

Harsono dan Tri Puji, 2009, "E-Bussiness dan E-Commercesebagai Trend Taktik Baru Perusahaan Bidang Multimedia”, Pusat Informasi Agribisnis Kementrian Pertanian dan Jurusan Sistem Informasi Fakulktas Ilmu Komputer, Universitas Bina Nusantara, Comm IT, Vol. 3, No. 2, Oktober 2009.

Munawir, S,2010, Analisis Laporan Keuangan, Yogyakarta, Libery. 